\title{
CAG News Page
}

\section{TIMES OF CHANGE AT THE CANADIAN ASSOCIATION OF GASTROENTEROLOGY}

The past few months have seen many significant changes in the administrative structure and infrastructure of the Canadian Association of Gastroenterology (CAG), but there are many more changes to come. With our new executive director, Paul Sinclair, in place in our new national office, several initiatives are underway to improve the ability of that office to serve the membership. In part, to signal these 'times of change', you will notice the use of a new logo for the CAG in this issue of the Journal, on the letterhead and on promotional materials. In the near future, major changes to the CAG Web site will be made. The Web site has been managed by Dr Jon Meddings since its inception a few years ago. We are very grateful to Jon for the many hours he has devoted to the site. However, in order for the Web site to grow, it is necessary that it be moved to a professional server that will permit a wider range of services to be used by our members (eg, online registration, submission of abstracts and manuscripts, access to the membership list, etc). The new Web site will also host a number of medical education programs that can be taken for accreditation points by members of the CAG. As has been mentioned previously in the "CAG News Page", significant changes to the structure of Canadian Digestive Disease Week will be instituted at the 2001 meeting. These changes are being made in response to the feedback provided by the attendees at the Quebec meeting.

\section{WORLD CONGRESS UPDATE}

Canada's bid for the 2005 World Congress of Gastroenterology was submitted in July. Montreal has been proposed as the venue for this event. The only other bid submitted was for Buenos Aires, Argentina. Site visits of Montreal and Buenos Aires will be conducted by the Organisation Mondiale de Gastro-Entérologie this autumn. If both bids are considered viable, a vote will take place at the World Congress meeting in Bangkok in 2002 to determine which city will host the 2005 meeting.

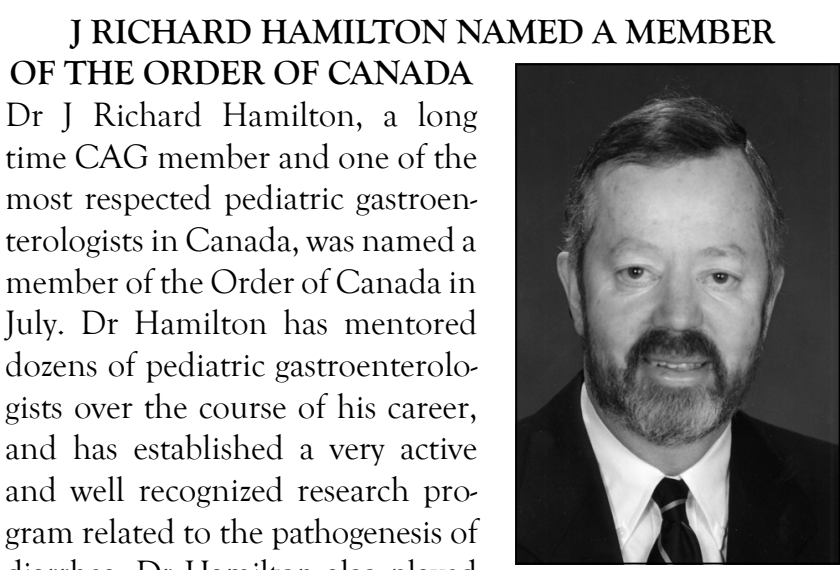
diarrhea. Dr Hamilton also played an instrumental role in the founding of the Canadian Foundation for Ileitis and Colitis (now known as the Crohn's and Colitis Foundation of Canada), which has grown to become one of the most important sources of research funding in gastroenterology in Canada. Several years ago, another CAG member and pediatric gastroenterologist, Dr Claude Roy, was honoured with the same award.

Please note the National Office e-mail has changed to: cagoffice@cag-acg.org 


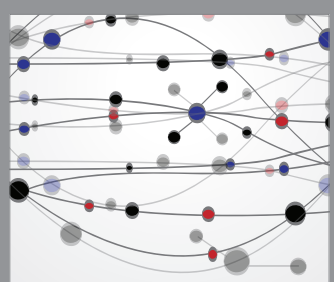

The Scientific World Journal
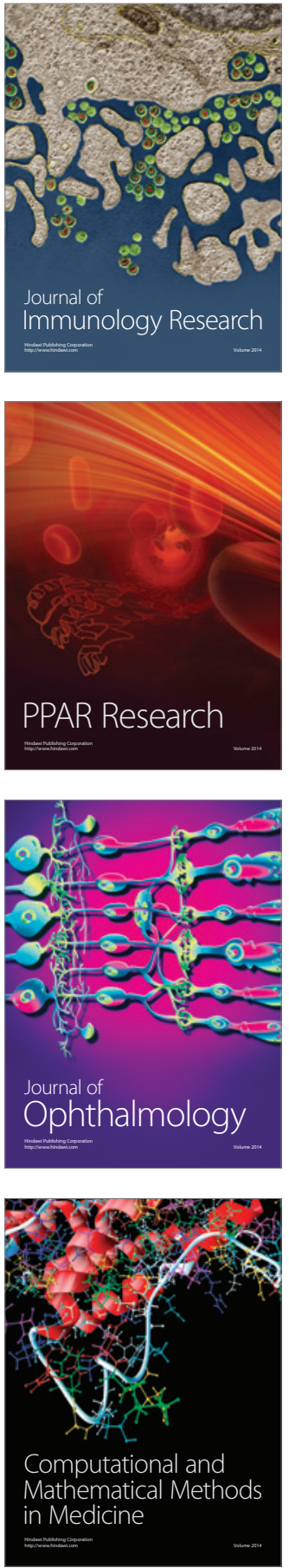

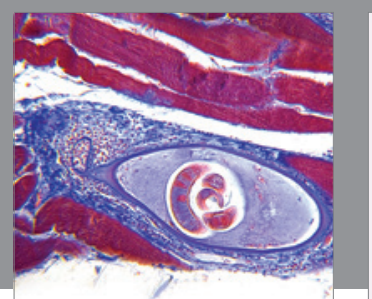

Gastroenterology Research and Practice

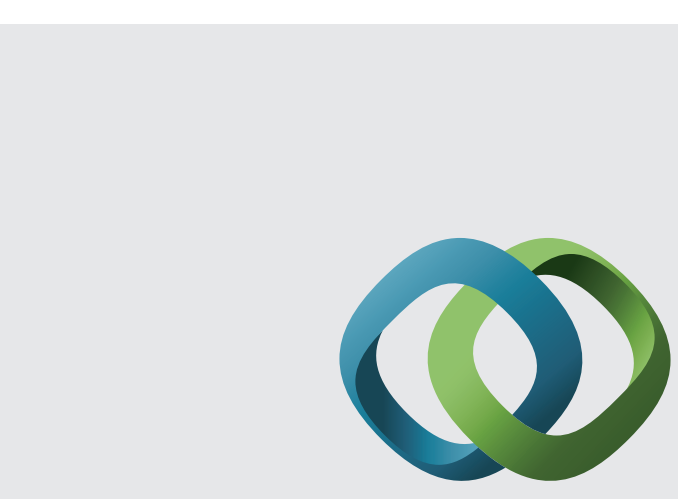

\section{Hindawi}

Submit your manuscripts at

http://www.hindawi.com
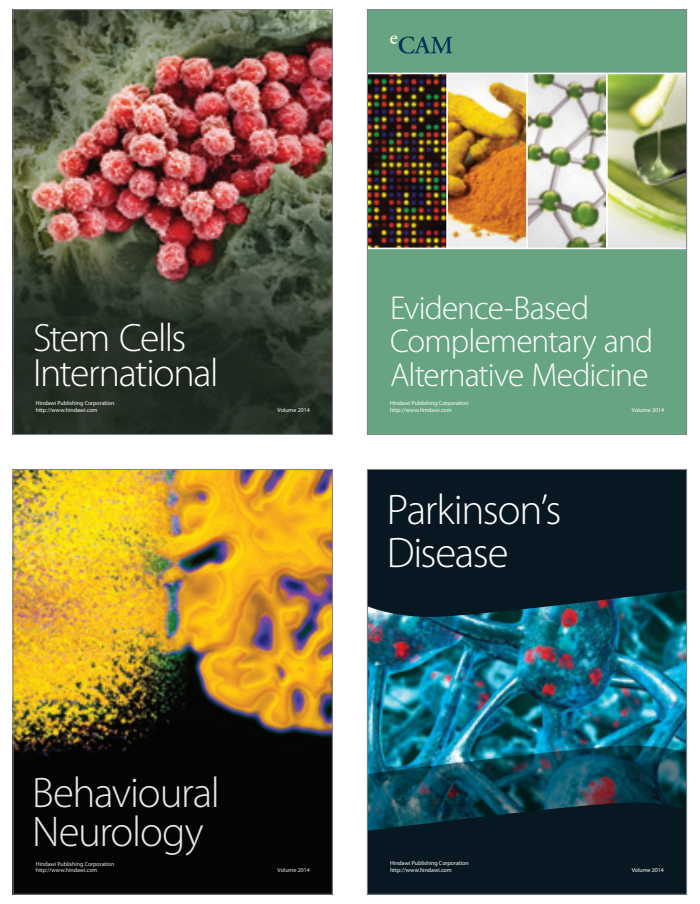
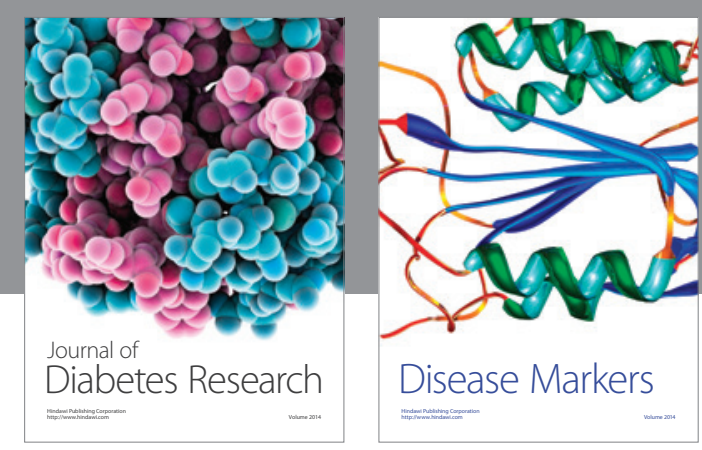

Disease Markers
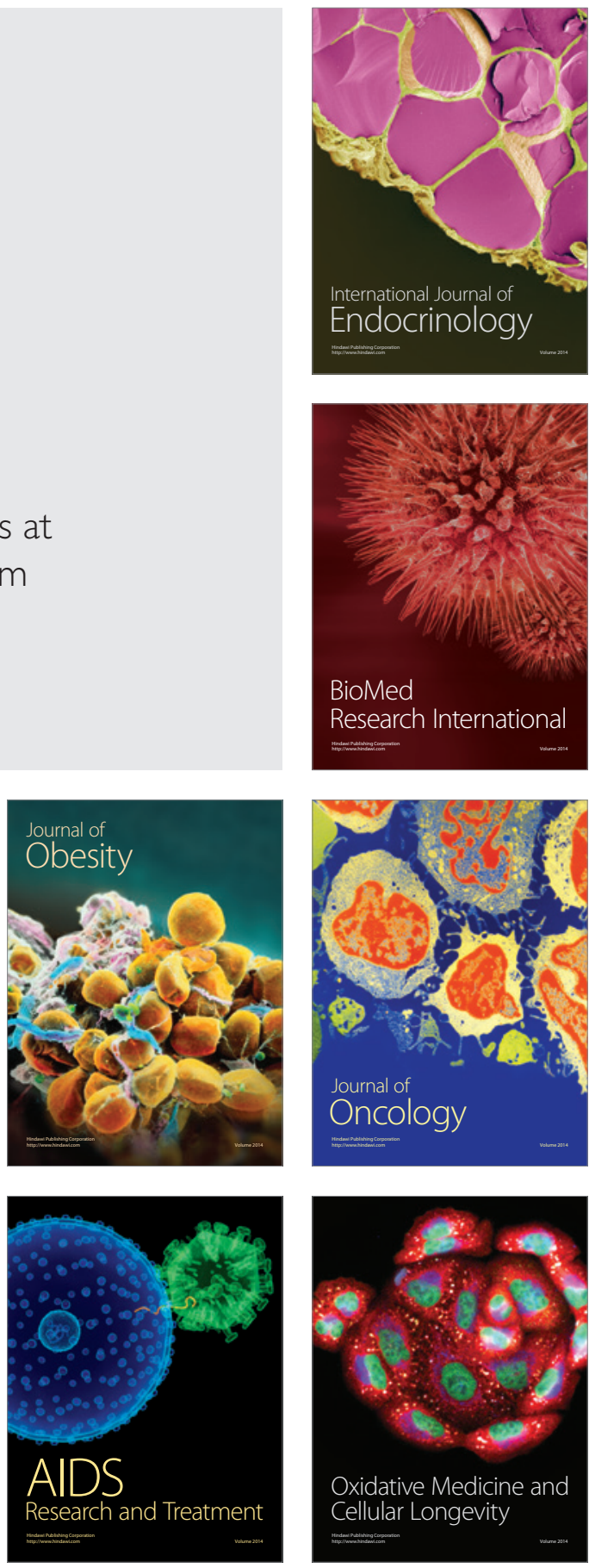